\title{
A CONSTRUÇÃO DIALÓGICA E PARADIGMÁTICA DA GOVERNANÇA SOLIDÁRIA LOCAL COMO PRESSUPOSTO DE EFICÁCIA DE UMÁ CIDADANIA ATIVA
}

Ricardo Hermany*

Dartagnan Limberger Costa*

\section{RESUMO}

Abordar a Governança Solidária Local é primordial na construção de um Estado Democrático. Muito se analisa da Administração Pública, as suas posturas gestacionais e suas habilidades dialógicas com todos os atores sociais, mas a experiência prática dessa consecução democrática se vislumbra, na atualidade, apenas no ideário de Governança Solidária Local, que vem, paulatinamente, desenvolvendo-se na capital gaúcha. Para entender essa nova postura do Poder Público Local, mister se faz uma análise de seus pressupostos fundacionais, principalmente pela alocação de capital humano, resplandecente da visão do Orçamento Participativo. Surge, ainda, dessa postura dialógica, in lócus, uma visão de consensualidade, em que se busca a emancipação social e a participação ativa da comunidade. A cidadania torna-se exercitável em decorrência do sentimento de participação na comunidade, na busca do bem comum geral.

Palavras-chave: Cidadania. Emancipação social. Governança solidária local. Orçamento participativo. Poder público local.

\section{INTRODUÇÃO}

Pretende-se com o presente ensaio trazer ao debate as possibilidades fundacionais da Governança Solidária Local em desempenhar conjunturas performativas de inclusão social, com vistas ao ideário de uma cidadania ativa.

Inicialmente, pretende-se discorrer sobre os pressupostos fundacionais do Programa de Governança Solidária Local na cidade de Porto Alegre, sua necessária relação com o capital social proveniente do Orçamento Participativo e sua postura emancipatória na inter-relação dialógica entre todos os atores sociais envolvidos.

Delimitadas as determinantes supra-estabelecidas, cabe ressaltar sua postura ativa na busca de uma cidadania plena, entendendo os aspectos do conceito de cidadania numa sociedade heterogênea e sua necessária relação com as políticas públicas de inclusão social. Olhar a cidadania sob um viés emancipatório e de forma ativa, decorrente da necessária inter-relação da Administração Pública, representada pelo município, na construção de um 
diálogo cidadão, entre todos os atores sociais, resguarda as prerrogativas prognosticadas do ideário da Governança Solidária Local.

\title{
1 PRESSUPOSTOS FUNDACIONAIS DO IDEÁRIO DE GOVERNANÇA SOLIDÁRIA LOCAL: UMA VISÃO HISTÓRICO-SOCIAL DAS PRERROGATIVAS SOCIOINCLUSIVAS DA NECESSÁRIA RELAÇÃO DIALÓGICA DOS ATORES SOCIAIS
}

Ao se estudar a Governança, deve-se ter em mente dois requisitos essenciais no trato da dialógica entre os atores sociais: democracia e respeito aos direitos fundamentais ${ }^{1}$.

\author{
Ensinam Santos Júnior, Azevedo e Queiroz Ribeiro que, segundo a \\ concepção de
}

[...] O’Donnell, na qual um regime democrático - ou poliárquico, na acepção de Dahl - tem duas dimensões fundamentais: primeiro, é um regime representativo de governo, em que o único mecanismo de acesso às principais posições de governo ocorre por meio de eleições competitivas, resultado da aposta institucionalizada, universalista e includente que faz uma sociedade, implicando a garantia a todos os indivíduos dos direitos de votar e de ser votado. Segundo, é um regime em que o sistema legal garante as liberdades e os direitos considerados fundamentais ao exercício da cidadania política. $^{2}$

Somente em um ambiente democrático poderão ser exteriorizadas as vontades e os pensamentos de uma determinada comunidade. O diálogo somente pode prosperar em ambientes passíveis de concretização dos debates, respeitadas as peculiaridades e os pensamentos de todas as pessoas nele envolvidas.

É com o diálogo, em um ambiente democrático, que pode florescer o que se denomina capital social. O termo capital social não é recente, pois tem como seu precursor o professor Lyda Johnson Hanifan, no longínquo ano de 1916. Entendia o professor que o capital social era de uma espécie de cooperativismo, em que o hábito das pessoas de se relacionarem, através de condutas positivas, criava uma rede de inter-relações para o bem-estar de toda a comunidade ${ }^{3}$.

Já James William Coleman ${ }^{4}$, tendo conhecimento dos ensinamentos de Hanifan, delimitava que a sociedade criaria vínculos que permitissem uma maior inter-relação entre as pessoas com seu meio, entendendo que o capital social não seria apenas uma entidade, mas um conjunto delas com dois traços em comum:

[...] todas elas consistem de algum aspecto das estruturas sociais, e elas facilitam certas ações de certos atores - sejam eles pessoas ou atores em agregado - dentro da estrutura. Como outras formas de capital, o capital social é produtivo, tornando possível a consecução de certos fins que na sua ausência não seriam possíveis. 
Mas, a notoriedade, que desencadeia o tema do capital social, vislumbra-se nos escritos de Robert Putnam ${ }^{5}$, em meados do ano de 1993, em que analisou as disparidades de desenvolvimento entre o sul e o norte da Itália.

Putnam analisa o processo de descentralização da Administração Pública na Itália. E os pressupostos políticos, administrativos e de desenvolvimento social nas áreas norte e sul do país.

Ensina Araújo que

Os estudos de Putnam envolveram técnicas e metodologias variadas
e cuidados sistemáticos para garantir a fidedignidade das
informações. Assim, durante vinte anos analistas acompanharam o
processo de implantação e os resultados do governo descentralizado
na Itália - descentralização essa que implicou a criação de vinte
regiões administrativas autônomas. ${ }^{6}$

Passado esse período, Putnam pôde vislumbrar que o Norte estava muito mais desenvolvido que o Sul. Ambos conseguiram avanços significativos, mas o Norte soube melhor aproveitar a descentralização desencadeada. Analisando tal prerrogativa, o autor passou a buscar a causa de tamanha disparidade. Em seu estudo pôde vislumbrar que o Sul permanecia com uma cultura política atrasada, baseada no clientelismo, na inépcia dos burocratas e na corrupção.

Como preleciona a autora, Putnam procurou compreender as diferenciações de desempenho institucional, muitas vezes recorrendo a outras variáveis, acabando por analisar a valorização da cultura cívica, a cultura política e as tradições existentes. Sendo assim, concluiu que o Norte teve maior desenvolvimento em decorrência dessas prerrogativas específicas.

Complementam Santos Júnior, Azevedo e Queiroz Ribeiro:

No referente à cultura cívica de participação, identificamo-nos com a abordagem de Robert Putnam. No seu clássico estudo sobre a reforma institucional da Itália, o autor conclui que o contexto social está relacionado à natureza da vida cívica, que denomina de "comunidade cívica", caracterizada "por cidadãos atuantes e imbuídos de espírito público, por relações políticas igualitárias, por uma estrutura social firmada na confiança e na colaboração". Nessa abordagem, a cultura cívica é a expressão não apenas das regras de reciprocidade, mas da corporificação de sistemas de participação social, formados pelas associações da sociedade organizada, que representam uma forma de capital social. ${ }^{7}$

Sendo assim, pode-se concluir que a cultura cívica poderia, associada à confiança interpessoal, beneficiar o grupo como um todo. Daí a idéia de criação de laços horizontais nas relações humanas.

Para além dessa visão interpessoal, ainda ensina Fukuyama $^{8}$, que é essa inter-relação social que permite, no mundo econômico, um barateamento nas transações de mercadorias. Ensina o autor, através do exemplo da cultura de confiança judaica, que uma pedra de diamante pode circular por diversas pessoas da comunidade e não ser surrupiada por algum dos membros. Isso 
causaria uma grande economia financeira, retirando os gastos com atravessadores e reforçando os laços de amizade dentro da comunidade.

Conclui Araújo que o capital social seria

[...] as relações informais e de confiança que fazem com que as pessoas ajam conjuntamente em busca de um bem comum, é fundamental para que novas e velhas organizações da sociedade civil possam prosperar e dar oportunidade de participação aos que ainda carecem de engajamento ou de proteção. ${ }^{9}$

$\mathrm{Na}$ sociedade civil contemporânea, o capital social está ligado veementemente à questão democrática, sobre a qual passaremos a dissertar em consonância com a delimitação do Orçamento Participativo.

Inglehart salienta que há níveis estatísticos entre a questão do desenvolvimento da confiança interpessoal e da democracia estável e o voluntarialismo social. Nesse sentido o autor ensina que "sociedades com altas taxas de pertencimento estão mais habilitadas a serem democracias estáveis que aquelas com baixas taxas de pertencimento."10

Ressalta Baquero que o capital social pode ser "uma alternativa potencial e viável de construção democrática mais eficiente, principalmente das camadas mais pobres [...]"11

Baquero tocou num ponto importantíssimo na presente análise, pois trata-se da visão democrática de que o capital social necessita para sua efetivação. As relações humanas, principalmente as de cunho decorrentes do grupo, necessitam ser abordadas sobre um viés democrático direto, atuando, todos os atores, de forma interligada e intermitente no diálogo entre si.

Em Porto Alegre, o projeto do Orçamento Participativo acabou por fomentar, com sua postura democrática, uma busca pela formação do capital social na cidade. Ensina Rogério Gesta Leal:

O orçamento participativo de Porto Alegre foi e é fruto de um processo de mudanças de paradigmas no âmbito das políticas públicas de gestão e inclusão social, aliado a uma nova forma de reflexão sobre o Estado e a sociedade no país. Suas estruturas funcionais e mesmo de concepção, foram se aperfeiçoando ao logo do tempo, notadamente em face de demandas, desafios e dificuldades que surgiram no percurso de sua efetivação. ${ }^{12}$

Os cidadãos das regiões abrangidas pelo programa interagem, através de votações, para alocação de recursos financeiros no que consideram mais prudente e necessário para suas comunidades. Trata-se de uma forma de diálogo e inclusão pela participação popular direta. 
Pode-se delimitar que o Orçamento Participativo é uma política pública que deu certo; no entender de González ${ }^{13}$, podemos ver dois fatores preponderantes que garantiram o sucesso dessa experiência em Porto Alegre: continuidade no tempo e histórico associativo.

Delimita González que "esta participação, mesmo que possa ter tido objetivos de reivindicação de bens instrumentais, em um primeiro momento, gerou como subproduto o crescimento do capital social destas comunidades". ${ }^{14}$

E é nesse ponto que se delimita a vertente histórico-fundante do capital social, como subproduto do Orçamento Participativo, na fomentação das bases interlocucionárias da Governança Solidária Local. Porto Alegre apenas se apresenta como detentora dos ideários desse novo projeto, em decorrência das condições de capital social preponderante na sua formação cidadã.

\title{
2 O PROJETO DE GOVERNANÇA SOLIDÁRIA LOCAL DE PORTO ALEGRE: UMA ANÁLISE CONCEITUAL DE SUA CONSTRUÇÃO E IMPLANTAÇÃO
}

$\mathrm{Na}$ atual gestão municipal, desde o ano de 2005, o programa vem sendo implantado, em parceria horizontal com o Orçamento Participativo, na construção dialógica dos pressupostos fundacionais de suas idéias democráticas, diferindo concomitantemente do ideário de sociedade adormecida ${ }^{15}$ que, infelizmente, notamos em grande parte de nossas cidades.

Santos Júnior, citando Pierre Hamel, ensina que, na atualidade, o termo Governança pode ser aferido da seguinte forma:

\begin{abstract}
[...] a noção de Governança sugere que a capacidade de governar não está unicamente ligada ao aparato institucional formal, mas supõe a construção de coalizões entre atores sociais, construídas em função de diversos fatores, tais como a interação entre as diversas categorias de atores, as orientações ideológicas e os recursos disponíveis. ${ }^{16}$
\end{abstract}

O termo Governança, na idéia do programa de governo da cidade, tem como objetivo uma relação de diálogo e paridade entre sociedade e governo, buscando a estimulação da participação social e a co-responsabilidade nas ações públicas. É Solidária, pois baseia-se na cooperação entre todos os atores sociais, agregando maior capital humano na formação de capital social. Trata-se de uma relação co-responsável construída no voluntariado da comunidade. E é Local, pois constrói redes intersetoriais e pautadas numa base territorial, constituída em regiões, bairros e vilas. ${ }^{17}$ Dessa forma, surge 0 aproveitamento do voluntariado na inter-relação comunicativa entre os atores sociais, formando um novo "orçamento", um orçamento de cunho humano, pois trata-se de mais recursos humanos na consecução dos ideários da 
comunidade, barateando a consecução dos projetos e emancipando socialmente os participantes.

Essa idéia de inter-relação dialógica entre a comunidade e o governo se apresenta no ideal trazido por Castells e Borja ${ }^{18}$, em que a comunicação permitiria a criação de laços, abrindo-se margem ao diálogo, propiciando uma grande rede entre os atores sociais. Idéia complementar se pode ver em Habermas $^{19}$, que acredita no diálogo e na busca da consensualidade, no âmbito público, para emancipação dos cidadãos. Bohman delimita categoricamente:

[...] sustento que a deliberação e o consenso seriam termos chaves à hora de definir a democracia e a política de governo ou de gestão, revelando-se fundamental que as razões de Estado e de cada grupo que o compõe possam resultar convincentes para o restante da cidadania $[\ldots]^{20}$

Couvaneiro nos traz outra característica fundamental do ideário da Governança, a idéia da cooperação. Para ela a cooperação é

[...] uma alternativa que visa regular a precariedade de meios e inserir socialmente os seus membros na sociedade, de forma a atribuírem-se valor e a sentirem-se causa, permitindo-lhes, ao mesmo tempo, acederem a condições de vida satisfatórias e encontrarem a liberdade da cidadania, responsável e consciente. ${ }^{21}$

Na Governança Solidária Local, o cidadão é parte, meio e fim de suas decisões e ações na construção de sua emancipação social.

É nesse sentido que Dewey ${ }^{22}$, somando-se a tal viés, salienta que o lócus da democracia é a comunidade, pois somente com a construção comunitária a cooperatividade pode trazer a real democracia e a emancipação do Ser Humano.

A isso se soma o capital social existente na cidade de Porto Alegre, onde se expressa a possibilidade de os indivíduos agirem de forma conjunta, cooperativamente, unidos através de um projeto comum e de interesse mútuo que os leva a fortalecer seus laços de confiança. Esse capital social valioso, entretanto, não está presente apenas na sociedade organizada. De fato, está presente também na tomada de consciência e ação cívica dos indivíduos autônomos, livres, aptos a posicionarem-se e a tomarem iniciativas tão variadas e diversas capazes de influenciar o meio a seu redor.

É através das ações de Governança que os cidadãos devem possuir sua participação amplamente valorizada nos momentos de colaborarem em fóruns que visem ao diagnóstico e às definições elaborativas de políticas públicas.

A Administração Pública tem o dever de incentivar tais posturas. Nesse sentido, determina Leal:

E é a própria Administração Pública que deve - e nosso sentir e destacadamente - criar condições à instituição de uma comunicação e linguagem decodificada e democrática, com o que permitirá a validação racional das questões normativas e operativas de suas 
ações - já não mais suas, mas de toda a comunidade -, isto porque, tal validez passa a ser compreendida como dependente de um processo intersubjetivo, regulado por razões e por posições tomadas racionalmente. ${ }^{23}$

A participação no debate público tem grande importância, como bem preleciona Habermas:

A política deliberativa obtém sua força legitimadora da estrutura
discursiva de uma formação de opinião e da vontade, a qual
preenche sua função social e integradora graças à qualidade
racional de seus resultados. Por isso, o nível discursivo do debate
público constitui a variável mais importante..$^{24}$

Mesmo os espaços de participação popular, previstos pelo ordenamento jurídico, como é o caso das audiências públicas no processo orçamentário, adquirem maior efetividade a partir de uma estratégia Local. Isso ocorre porque a esfera Local permite um processo maior de comunicação e controle social, devendo-se ressalvar, contudo, a necessidade de um patamar institucional, referencial capaz de conciliar, pelas razões já expostas, estratégias participativas com institutos próprios do modelo representativo.

De fato, nas esferas mais determinadas, de menor extensão, é possível uma efetiva participação dos atores sociais considerados excluídos ou incapazes de fazer frente ao processo complexo de articulação nos espaços nacional e, especialmente, transnacional.

Talvez, o que melhor explique a atual postura de descentralização do poder, em multifacetadas instâncias, decorra principalmente, como esclarece Castells e Borja ${ }^{25}$, da necessidade de proximidade entre o governo e os seus cidadãos, visando e criando laços comunicativos que permitam o diálogo.

Amaral $^{26}$ considera 0 fortalecimento do empoderamento Local como condição de existência da democracia, o que basta para demonstrar a importância das regras sobre gestão democrática da cidade para a efetividade da democracia participativa estabelecida pela Constituição Federal.

A percepção do espaço Local, como elemento-chave, está intimamente associada ao processo de democratização do país, em que se configura a compreensão e constituição das formas administrativas municipais e descentralizadas, enquanto espaço político e institucional das políticas sociais. ${ }^{27}$ É nesse sentido que, no campo das políticas públicas, se tem como uma das principais inovações o elevado grau de participação popular nos diferentes níveis de desenvolvimento e implementação das políticas.

A intensificação da ação e da participação dos "clientes" nas políticas de Welfare parece estar constituindo, em quase todo o mundo, tendência a diminuir o grau de passividade com que anteriormente eram aquelas recebidas e, mais do que 'dinamizar' os direitos sociais, rearticulam o espaço, a trama social na qual se processam as políticas. [...] Em outras palavras, as associações de vizinhança, de moradia, os organismos comunitários, as organizações voluntárias de todo o tipo que se formam nas e para as políticas 
sociais estariam expressando aquele movimento social mais profundo de contínua reorganização do tecido social [...]..$^{28}$

A cidade de Porto Alegre agrega-se ao federalismo nacional, com um diferencial substancial nesse período de nossa contemporaneidade, pois acumula muito capital social para ingressar em uma nova fase de inclusão social através da consensualidade entre todos os atores sociais envolvidos na relação comunicativa. Afinal, como ensina Habermas: "No sistema da Administração Pública concentra-se um poder que precisa regenerar-se a cada passo a partir do poder comunicativo." ${ }^{29}$. A justificativa do poder da Administração Pública encontra-se nas pessoas que formam o conjunto, a unidade social.

Ensina Feijón ${ }^{30}$ que, mesmo que haja uma relação mais ampliativa do diálogo entre os atores sociais, a municipalidade tem papel importante na gestão desses interesses, dando maior ênfase na construção de um projeto de interesses comuns, evitando a centralização do poder na mão de uma gestão. O funcionamento do projeto $^{31}$ se baseia na construção estruturada e racional do consenso, deixando de lado as velhas formas adversalistas que não realizam uma função realmente integratória e emancipatória na comunidade. Interessante ressaltar que há nesse projeto uma visão diferente daquilo que normalmente se chama de utilitarismo empresarial, o que, na verdade, seria uma forma de utilizar apenas a empresa como propulsora financeira dos projetos.

A Governança Solidária Local não é excludente de nenhum ator social, pois todos interagem na medida de sua capacidade para buscar o consenso, até mesmo os empresários da região. Independentemente da visão utilitarista das empresas em atuarem como atoras sociais junto às suas comunidades, nelas cresce a visão de consciência cidadã nas mesmas. O projeto de Governança Solidária Local passa a interagir de forma que o empresariado não seja mais um mero financiador dos projetos pré-prontos, estabelecidos por líderes comunitários com a prefeitura; a empresa passa a ser parceira na construção do consenso e na formação de uma política responsável e social para o meio onde reside.

A Governança Solidária, como delimita Feijós ${ }^{32}$, destrava a questão anteriormente deturpada de uma ação eminentemente governamental, regida pelos ditames meramente alocatórios de capital financeiro público em uma certa prioridade, esquecendo-se, muitas vezes, do futuro da comunidade. Nesse novo projeto, de cunho democrático, o Estado está presente como responsável por ofertar políticas e serviços públicos, não sendo ele o único responsável pelo desenvolvimento Local e pela sustentação de uma comunidade. O projeto chama à baila os cidadãos das comunidades para assumirem suas responsabilidades, sendo o Estado cooperante na busca do desenvolvimento da comunidade.

Ainda afirma a autora:

A Governança Solidária Local oferece a possibilidade de serem levados em conta todos os recursos públicos de uma comunidade além de estimular o espírito empreendedor, a co-responsabilidade e 
a participação de uma agenda de prioridades com vistas à sua emancipação. ${ }^{33}$

E é nessa linha que podemos adentrar na dialogia entre o Programa de Governança Solidária Local e a consecução do ideário de cidadania almejado pela comunidade.

\title{
3 O PARADIGMA DA GOVERNANÇA SOLIDÁRIA LOCAL NA CONSECUÇÃO DA CIDADANIA ATIVA DE CỦNHO MUNICIPAL
}

Acredita-se que a visão de cidadania tem uma relação intermitente e delineadora de sua constituição através da municipalidade. O município, como lócus privilegiado de intercomunicação social, é o ente mais próximo da comunicação e da inter-relação dialógica entre os atores sociais.

É no município que os munícipes poderão melhor exercer sua cidadania e cobrar a efetividade do município. Périus é enfático ao asseverar a potencialidade municipal como gerência predominante da vida intersubjetiva, pessoal e laboral do cidadão:

\begin{abstract}
É no município que o homem nasce, vive e morre. Recebe os primeiros serviços da saúde, da educação. É no município que somos cidadãos, expressamos nossa cidadania, exercemos nossos direitos mais elementares e cumprimos nossos deveres mais essenciais. Chegou a hora, portanto, de mudar, começando a definir um novo Brasil a partir da célula básica, que é o município. Com mais recursos, com independência administrativa, alcançar-se-á uma democracia mais participativa, soluções mais rápidas e mais adequadas aos interesses dos cidadãos, e por certo haverá menos burocracia e mais controle direto sobre as ações administrativas do Poder Executivo e maior participação no Poder Legislativo, pois prefeitos e vereadores vivem mais junto à população, sentem de perto os problemas de seus habitantes e convivem com sua cultura e a sua história. ${ }^{34}$
\end{abstract}

São justamente os governos locais os responsáveis pela execução de políticas públicas adequadas para o fortalecimento da qualidade de vida, seja em função da (re) definição de competências constitucionais, seja em virtude da crise de financiamento do Estado Nacional, que o incapacita de atender com efetividade às demandas da população. Tais razões justificam a importância, até paradoxal, do poder Local para o desenvolvimento econômico na sociedade globalizada, vinculado ao conceito de qualidade de vida como fator de produtividade e, por conseguinte, de eficiência do sistema produtivo. ${ }^{35}$

Previsto de forma expressa a partir do art. 29 da Constituição Federal, o ordenamento jurídico brasileiro consagra a organização sociopolítica em nível Local, tanto que prevê a prerrogativa de um autogoverno na esfera municipal, envolvendo o amplo espectro das decisões públicas, ou seja, as atribuições legislativas e administrativas em seu sentido lato, inclusive a gestão financeira ${ }^{36}$, pontos centrais dessa obra. Diante disso, verifica-se a previsão de uma auto-organização primária, ou seja, oriunda das determinações do 
constituinte originário, que estabeleceu a prerrogativa de os Municípios regerem-se por uma Lei Orgânica, elaborada pela Câmara Municipal.

O Município, portanto, possui competências exclusivas, cumulativas e, em diversos casos, a possibilidade do exercício de competência constitucional suplementar. Mas, é no conjunto de atribuições constitucionais exclusivas ou privativas do Município que se encontram algumas discussões doutrinárias de extremo interesse, para que se definam quais são as atividades que competem constitucionalmente ao Município, bem como se verifiquem os limites encontrados para sua consolidação ${ }^{37}$.

O espaço Local, como se pode observar, além de favorecer a construção da responsabilidade social, potencializada pelo sentimento de solidariedade e pertencimento, por parte dos atores que integram a sociedade civil, contribui para a efetividade do controle social. Se, por um lado, o direito social se manifesta na tomada de decisões públicas a partir de uma construção compartilhada, da mesma forma assume destaque 0 controle e 0 acompanhamento da execução das políticas públicas definidas em parceria com a sociedade.

Contudo, é fundamental a leitura dos instrumentos de gestão democrática da cidade para além da ótica da regulação da propriedade no espaço urbano, tendo maior importância, para a construção de um direito social, uma análise mais aberta dos espaços de participação. Dessa forma, a abordagem dos instrumentos de gestão democrática deve estar mais vinculada à idéia ampla de função social da cidade, da qual a propriedade é apenas um dos elementos integrantes, possibilitando-se, com essa postura, a atribuição de sentido ao princípio da dignidade da pessoa humana, bem como da cidadania.

Atualmente, o Poder Local deve, dentro de suas competências, promover o diálogo entre seus cidadãos na promoção da cidadania. E dever do Estado, para realização da função social da cidade democrática, aquela amparada e construída pelo ideário comunitário, sob viés horizontalizador, promover formas de participação pública de construção do social. Trata-se de uma promoção da participação cidadã.

Elenaldo Teixeira ${ }^{38}$ entende que a participação cidadã é um mecanismo importante em que se redefinem os papéis. Vejamos:

[...] participação cidadã: processo complexo e contraditório entre sociedade civil, Estado e mercado, em que os papéis se redefinem pelo fortalecimento dessa sociedade civil mediante a atuação organizada dos indivíduos, grupos e associações. Esse fortalecimento dá-se, por um lado, com a assunção de deveres e responsabilidades políticas específicas e, por outro, com a criação e exercício de direitos. Implica também o controle social do Estado e do mercado, segundo parâmetros definidos e negociados nos espaços públicos pelos diversos atores sociais e políticos.

Aprofundando-se na questão da cidadania, parte fundamental e pressuposto almejado para a consecução do ideário de dignidade da pessoa humana, nos atrelamos à idéia de cidadania aos moldes de Corrêa, que nos ensina: 
A cidadania, pois, significa a realização democrática de uma sociedade, compartilhada por todos os indivíduos ao ponto de garantir a todos o acesso ao espaço público e condições de sobrevivência digna, tendo como valor-fonte a plenitude da vida. Isso exige organização e articulação política da população voltada para a superação da exclusão existente. ${ }^{39}$

Não adentraremos firmemente na questão histórica do processo de conceituação, inacabado, do que representa a cidadania; apenas atemo-nos a delimitar que o conceito contemporâneo, como bem prelecionado por Corrêa, emerge de um ideário burguês, onde se buscava ampliar os espaços de interação da sociedade civil, protegendo e ampliando as idéias dessa classe.

Marshall ${ }^{40}$ define a cidadania como "um status concedido àqueles que são membros integrais de uma comunidade. Todos aqueles que possuem o status são iguais com respeito aos direitos e obrigações pertinentes ao status." Tal status deriva do ideário burguês de liberdade e igualdade formais.

Interessante que no capitalismo aceitamos a pobreza como desmerecimento, fracasso e indigência, procurando no máximo diminuir, como preleciona Corrêa, a influência das classes, mas sem atacar o sistema delas. Marshall conclui esse pensamento desferindo forte crítica:

Aumentou o nível do piso no porão do edifício social e, talvez, o tornou mais higiênico do que antes. Mas continuou sendo um porão, e os andares mais elevados do prédio não foram afetados. E os benefícios recebidos pelos infelizes não se originaram de um enriquecimento do status da cidadania. ${ }^{41}$

É nesse diapasão que podemos vislumbrar o poder de influência das políticas públicas em criar mecanismos sócio-inclusivos, permissivos da consecução dialógica, dentro do espaço público, de tanger os interesses dos membros da comunidade, com fins emancipatórios.

A Governança Solidária Local permite a interlocução, dentro do espaço público, somando-se capital social e humano, para consecução do ideário de uma cidadania ativa, pois amplia a participação dos atores sociais na busca pelos objetivos sócio-inclusivos e emancipatórios vislumbrados pelo consenso racional. Somente essa forma de interação que permite que os moradores das comunidades pelo Programa abrangidas, até mesmo os "desqualificados", como preleciona Paugam ${ }^{42}$, tenham possibilidade de dialogar sobre o que pensam ser de relevância para sua comunidade.

A Governança pretende fomentar a criação de cidadãos, permitindo sua interação no meio em que vivem, possibilitando a busca do bem-comum. Ser cidadão contemporaneamente é muito mais que um simples voto ou uma possibilidade de ser eleito. 


\title{
CONCLUSÃO
}

Diante das delimitações consecutórias supra-delimitadas, podemos vislumbrar uma inter-relação intrínseca no ideário da Governança Solidária Local com objetivos formativos dos cidadãos. Atualmente, não existe outra forma de interação sócio-inclusiva, eficaz, que não seja a forma dialógica racional, amparada na consubstancial consensualidade social.

O ideário da Governança Solidária Local pretende utilizar todo o capital humano decorrente do capital social e das prerrogativas dialógicas e consensuais para ampliar e fomentar espaços de inclusão social. A cidadania passa a ser exercida em sua plenitude, visando consubstancialmente ao bem comum da própria comunidade.

A comunidade como um todo se valoriza no ideário de formação primordial do consenso; a idéia do conhecer, dialogar e interagir acaba por fomentar a utilização de todos os recursos passíveis de consecução do ideário emancipatório dos integrantes da comunidade.

Ser cidadão não é ser taxado por uma definição predefinida, ou pela capacidade de votar e ser votado, mas pela capacidade humana de trabalhar e solidarizar-se com o bem-comum em seu ambiente. São as relações dialógicas intra-substanciais que permitem a todos da comunidade a devida consecução, pelo ideário de Governança Solidária Local, serem consideradas realmente cidadãos.

\section{THE DIALOGICAL CONSTRUCTION AND PARADIGMATIC OF LOCAL SOLIDARITY GOVERNANCE ASSUMPTION EFFECTIVENESS OF AN ACTIVE CITIZENSHIP}

\begin{abstract}
Addressing the Local Solidarity Governance is paramount in building a Democratic State. Much has been analyzing the government, their attitudes and skills of management dialogue with all social actors, but the practical experience of democratic achievement in sight, in actuality, only the ideals of Local Solidarity Governance, which is, slowly, building up in Porto Alegre. To understand this new attitude of the Local Government, first must need an analysis of their foundational assumptions, mainly by the allocation of human capital, resplendent view of the Participatory Budget. Dialogical vision that emerges on the spot, a position of consensuality where demand for social emancipation and the active participation of the community.. Citizenship becomes true due to the sense of participation in the community, seeking the common good in general.
\end{abstract}


Keywords: Citizenship. Local Social Emancipation. Local Solidary Governance. Participatory Budget. Public Power.

\section{NOTAS}

Professor do Programa de Pós-Graduação em Direito - Mestrado - da Universidade de Santa Cruz do Sul e Doutor pela Universidade do Vale do Rio dos Sinos com estágio de doutoramento pela Universidade de Lisboa. Coordenador do sub-grupo de Estudos Possibilidades e Perspectivas de Consolidação do Princípio Federativo a partir do Paradigma da Governança Local, do Grupo Estado, Administração Pública e sociedade (CNPQ).

"* Mestrando em Direito da Universidade de Santa Cruz do Sul. Membro do sub-grupo de Estudos Possibilidades e Perspectivas de Consolidação do Princípio Federativo a partir do Paradigma da Governança Local, do Grupo Estado, Administração Pública e sociedade (CNPQ).

1 SANTOS JÚNIOR, Orlando Alves. Governança democrática e poder Local: a experiência dos conselhos municipais no Brasil. Rio de Janeiro: Revan, Fase, 2004.

2 SANTOS JÚNIOR, O. A.; AZEVEDO, S.; QUEIROZ RIBEIRO, L. C. Democracia e gestão Local: a experiência dos conselhos municipais no Brasil. In: Governança democrática e poder Local: a experiência dos conselhos municipais no Brasil. Rio de Janeiro: Revan, Fase, 2004, p. 15.

3 HANIFAN, Lyda Johnson. The rural school community center. In: Annals of the American Academy of Political and Social Science, $\mathrm{n}^{\circ}$. 67, 1916.

4 COLEMAN, James. Foundations of social theory. Cambridge: The Belknap Press of Havard University Press, 1994.

5 PUTNAM, Robert. Making Democracy Work: Civic Traditions in Modern Italy, EDITORA. 1993.

6 ARAÚJJ, Maria Celina Soares D'. Capital Social. Rio de Janeiro: Jorge Zahar, 2003, p. 13.

7 SANTOS JÚNIOR, O. A.; AZEVEDO, S.; QUEIROZ RIBEIRO, L. C. Democracia e gestão Local: a experiência dos conselhos municipais no Brasil. In: Governança democrática e poder Local: a experiência dos conselhos municipais no Brasil. Rio de Janeiro: Revan, Fase, 2004, p. 17.

8 FUKUYAMA, Francis. Confiança: As virtudes sociais e a criação da prosperidade. Rio de Janeiro, Rocco, 1996.

9 ARAÚJO, Maria Celina Soares D'. Capital Social. Rio de Janeiro: Jorge Zahar, 2003, p. 45.

10 INGLEHART, Ronald. Modernization and postmodernization: cultural, economic, anda political chance in 43 societies. Princeton: Princeton University Press, 1997, p. 190.

11 BAQUERO, Marcello. Capital social na América Latina. In: BAQUERO, Marcello (org.) Reinventando a sociedade na América Latina: cultura política, gênero, exclusão e capital social. Porto Alegre/Brasília: Ed. Universidade/Conselho Nacional de Direitos da Mulher, 2001, p. 58.

12 LEAL, Rogério Gesta. Estado, Administração Pública e sociedade: novos paradigmas. Porto Alegre: Livraria do Advogado, 2006, p. 157.

13 GONZÁLEZ, Rodrigo. Capital social, ação coletiva e orçamento participativo. In: BAQUERO, Marcello (org.) Reinventando a sociedade na América Latina: cultura política, gênero, exclusão e capital social. Porto Alegre / Brasília: Ed. Universidade/Conselho Nacional dos Direitos da Mulher, 2001.

14 Idem, p. 168.

15 LEAL, Rogério Gesta. Os pressupostos espistemológicos e filosóficos da gestão de políticas públicas no estado democrático de direito. In: Direitos sociais e políticas públicas: desafios contemporâneos. Santa Cruz do Sul: EDUNISC, 2003, p. 821.

16 SANTOS JUNIOR, Orlando Alves. Democracia e Governo Local - Dilemas da Reforma Municipal do Brasil. 1. ed. Rio de Janeiro: Editora Revan; Co-edição IPPUR/UFRJ-FASE, 2001, p. 60.

17 Disponível em <http://www2.portoalegre.rs.gov.br/smgl/default.php?p_secao=4> Acesso em 14 de Abril de 2008. 
CASTELLS, Manuel, BORJA, Jordi. As Cidades como Atores Políticos. Novos Estudos CEBRAP: São Paulo, 1996, p. 158.

19 HABERMAS, Jürgen. Teoria de la Accion Comunicativa. Madri: Taurus, 2000.

20 BOHMAN, James. Public Deliberation: Pluralism, Complexity, and Democracy. Boston: Madinson, 2002, p. 13.

21 COUVANEIRO, Maria da Conceição Henriques Serrenho. As práticas cooperativas: mudanças pessoais e sociais. Instituto António Sérgio do Sector Cooperativo - INSCOOP. Pensamento Cooperativo. O Terceiro Sector em Portugal. In:Revista de Estudos Cooperativos, n.ำ 2, Lisboa, 2001, p. 35.

22 DEWEY, John. Democracia cooperativa: escritos políticos escolhidos de John Dewey : 1927-1939 / Augusto de Franco, Thamy pogrebinschi (organizadores). Porto Alegre: EDIPUCRS, 2008, p. 23. bdem, p. 857.

HABERMAS, Jurgen. Direito e democracia: entre a/actividade e a validade. Rio de Janeiro, Tempo Brasileiro, 2 v. Tradução de Factivity and Validity: Flávio Beno Siebeneichler. 1997, p. 28.

25 Ibidem, p. 158.

26 AMARAL, Roberto. A democracia representativa está morta; viva a democracia participativa. In: GRAU, Eros Roberto; GUERRA FILHO, Willis Santiago (coord.). Direito Constitucional: estudos em homenagem a Paulo Bonavides. São Paulo: Malheiros, 2003, p. 23.

27 DRAIBE, Sônia Miriam. As políticas sociais brasileiras: diagnósticos e perspectivas. In: Para a Década de 90 - Prioridades e Perspectivas de Políticas Públicas. Políticas Sociais e Organização do Trabalho, 4, Brasília: IPEA/IPLAN, 1990, p. 36. Ibidem, p. 36

29 HABERMAS, Jürgen. Direito e Democracia: Entre Faticidade e Validade. Tradução de Flávio Beno Siebeneichler. Rio de Janeiro: Tempo Brasileiro, 1997, p. 215.

30 FEIJÓ, Jandira. A essência da Governança Solidária Local. In: Olhares sobre a experiência da Governança Solidária Local de Porto Alegre. Porto Alegre: EDIPUCRS, 2008.

${ }^{31}$ Passo 1 - Sensibilização e Capacitação. A implantação propriamente dita do programa começa com a sensibilização dos Secretários Municipais, Secretários Adjuntos e Coordenadores de Secretarias e com a capacitação dos agentes animadores iniciais dessas redes, os supervisores, os articuladores em cada região, os Comitês Gestores governamentais e os Gerentes de Programas da Prefeitura Municipal de Porto Alegre. Supervisores e articuladores da GSL serão capacitados como multiplicadores do programa para que possam dar seguimento à capacitação dos participantes das Redes de Governança Solidária Local em todas as 17 regiões. Haverá apenas 5 Supervisores, que se dedicam a acompanhar o trabalho de 17 Articuladores. Supervisores e Articuladores são capacitados como agentes multiplicadores da presente metodologia. Passo 2 - Equipe de Articulação. Em seguida ocorre a constituição das Equipes de Articulação das Redes de GSL em cada uma das 17 regiões. Dessa equipe participam o Comitê Gestor e pessoas representativas das organizações da sociedade civil, das empresas e das demais instituições do Estado presentes na região. Passo 3 - Rede de Governança Solidária Local. A primeira tarefa de cada Equipe de Articulação é estimular a construção da Rede de Governança Solidária Local na sua região. Dessa rede podem participar, voluntariamente, lideranças representativas dos bairros abarcados pela região numa proporção de 1/1000. Assim, por exemplo, na Rede de Governança Solidária Local da Região Partenon, devem estar conectadas, pelo menos, 120 pessoas, pois esse número corresponde a um milésimo das 120 mil pessoas que moram, trabalham ou atuam nos bairros que compõem a região: Cel. Aparício Borges (15 mil pessoas), Partenon (47 mil pessoas), Santo Antônio (15 mil pessoas), São José (30 mil pessoas) e Vila João Pessoa (13 mil pessoas). As pessoas conectadas nas Redes de Governança Solidária Local deverão ser inscritas formalmente, serão informadas regularmente do andamento da implantação do programa, terão a função de validar - ou não - tudo o que for produzido pelas respectivas Equipes de Articulação e serão chamadas a participar das reuniões gerais e, sobretudo, das ações coletivas que forem programadas e encaminhadas. As pessoas conectadas nas Redes de Governança Solidária Local serão capacitadas, progressiva e permanentemente, pelos multiplicadores das suas Equipes de Articulação. Passo 4 - Seminários Visão de Futuro. A segunda tarefa da Equipe de Articulação é realizar, com a ajuda do articulador e do seu supervisor, o Seminário Visão de Futuro. Esse seminário deverá ser feito em no mínimo oito horas de 
trabalho em uma oficina especialmente dedicada ao assunto. Nessa oficina, usando métodos participativos já largamente testados em iniciativas de desenvolvimento Local, os participantes serão estimulados a sonhar um futuro desejado para a região tendo como horizonte estratégico o prazo de 10 anos que coincide com o prazo para o alcance das Metas de Inclusão Social da Prefeitura de Porto Alegre sintonizadas com às Metas do Milênio da ONU. É a partir desse seminário que será plantada a semente de uma comunidade de projeto em cada região. Uma vez elaborada participativamente uma visão de futuro coletiva pela Equipe de Articulação em cada região, esse sonho de futuro será compartilhado com a Rede de Governança Solidária Local respectiva para ser validado. Passo 5 - Diagnóstico dos Ativos e Necessidades. A terceira tarefa da Equipe de Articulação é realizar o Diagnóstico dos Ativos e das Necessidades da sua região. A elaboração desse diagnóstico é uma tarefa prática, feita com trabalho de campo e muitas oficinas, lançando mão de metodologias participativas já consagradas. O Diagnóstico dos Ativos e das Necessidades será feito no prazo de 30 dias. Novamente aqui, uma vez elaborado o diagnóstico pela Equipe de Articulação em cada região, ele será compartilhado com a Rede de Governança Solidária Local respectiva para ser validado. Passo 6 - Plano Participativo e Metas A quarta tarefa da Equipe de Articulação é elaborar, com base no Diagnóstico mencionado no passo anterior, o Plano Participativo e estabelecer as Metas a serem atingidas ao longo do tempo. Cada região escolherá o(s) seu(s) eixos prioritários de desenvolvimento e projetará as ações a serem desenvolvidas, dentro do horizonte temporal considerado, para atingir suas metas. Novamente aqui todo o produto final desse trabalho será submetido à Rede de Governança Solidária Local. Passo 7 - Agenda de Prioridades A quinta tarefa da Equipe de Articulação é formular a sua Agenda de Prioridades para 0 próximo ano. Essa agenda decorre do Plano Participativo mas incorpora também outras ações do poder público ou da sociedade Local que estejam em curso ou previstas. A elaboração do Plano Participativo (com suas Metas) e a formulação da Agenda de Prioridades deverá ser realizada, igualmente, em 30 dias. Como nos outros passos de implantação do Programa, todos esses produtos deverão ser validados pela Rede de Governança Solidária Local em cada região. Passo 8 - Celebração do Pacto pela Governança Solidária Local. A sexta tarefa da Equipe de Articulação é organizar a celebração do Pacto pela Governança Solidária Local. Dessa celebração participarão todos os membros da Rede de Governança Solidária Local e todos os parceiros, governamentais, empresariais e da sociedade civil e das demais instituições de apoio e fomento que estiverem comprometidos com a realização da Agenda de Prioridades. $O$ Pacto pela Governança Solidária Local também representa a formalização dos compromissos assumidos por todos os participantes na consecução das ações contidas na Agenda de Prioridades. Disponível em Iproweb.procempa.com.br/pmpa/prefpoa/smgl/usu_doc/Local_solidary_governance_texto_ original.pdf. (acesso em 0102 2008).

32 Idem.

33 Ibidem, p. 18.

34 PERIUS, Vergílio Frederico. Cooperativismo e lei. São Leopoldo: Editora UNISINOS, 2001, p. 274.

35 HERMANY, Ricardo. (Re)discutindo o espaço Local.uma abordagem a partir do direito social de Gurvitch. Santa Cruz do Sul: Edunisc/IPR, 2007.

36 Esta municipalização da gestão financeira mostra-se essencial para a análise dos instrumentos de democratização da gestão fiscal a partir do poder Local, destacando-se a obrigatoriedade da realização de audiências públicas na elaboração e discussão das leis orçamentárias (PPA, LDO e LOA).

37 Importante é esclarecer que, apesar dos avanços verificados em sede constitucional, existem diversos aspectos a serem observados, especialmente em função de um histórico extremamente centralizador da Federação Brasileira.

38 TEIXEIRA, Elenaldo Celso. O Local e o global: limites e desafios da participação cidadã. 2. ed. São Paulo: Cortez; Recife : EQUIP ; Salvador : UFBA, 2001, p. 30.

39 CORRÊA, Darcísio. A construção da cidadania: reflexões histórico-políticas. ljuí: Unijuí, 2006, p. 217.

40 MARSHALL, T. H. Cidadania, classe social e status. Trad. De Meton Porto Gadelha. Rio de Janeiro: Zahar Editores, 1967, p. 76

41 Idem, p. 78/79 
PAUGAM, Serge. La disqualification socieale (Essais sur la nouvelle pauvreté). Paris: PUF, 1991.

\section{REFERÊNCIAS}

AMARAL, Roberto. A democracia representativa está morta; viva a democracia participativa. In: GRAU, Eros Roberto; GUERRA FILHO, Willis Santiago (coord.). Direito Constitucional: estudos em homenagem a Paulo Bonavides. São Paulo: Malheiros, 2003

ARAÚJO, Maria Celina Soares D'. Capital Social. Rio de Janeiro: Jorge Zahar, 2003.

BAQUERO, Marcello. Capital social na América Latina. In: BAQUERO, Marcello (org.) Reinventando a sociedade na América Latina: cultura política, gênero, exclusão e capital social. Porto Alegre/Brasília: Ed. Universidade/Conselho Nacional de Direitos da Mulher, 2001

BOHMAN, James. Public Deliberation: Pluralism, Complexity, and Democracy. Boston: Madinson, 2002

CASTELLS, Manuel, BORJA, Jordi. As Cidades como Atores Políticos. Novos Estudos CEBRAP: São Paulo, 1996

COLEMAN, James. Foundations of social theory. Cambridge: The Belknap Press of Havard University Press, 1994.

COUVANEIRO, Maria da Conceição Henriques Serrenho. As práticas cooperativas: mudanças pessoais e sociais. Instituto António Sérgio do Sector Cooperativo - INSCOOP. Pensamento Cooperativo. O Terceiro Sector em Portugal. In:Revista de Estudos Cooperativos, n.. 2, Lisboa, 2001

CORRÊA, Darcísio. A construção da cidadania: reflexões histórico-políticas. ljuí: Unijuí, 2006.

DEWEY, John. Democracia cooperativa: escritos políticos escolhidos de John Dewey : 1927-1939 / Augusto de Franco, Thamy pogrebinschi (organizadores). Porto Alegre: EDIPUCRS, 2008

DRAIBE, Sônia Miriam. As políticas sociais brasileiras: diagnósticos e perspectivas. In: Para a Década de 90 - Prioridades e Perspectivas de Políticas Públicas. Políticas Sociais e Organização do Trabalho, 4, Brasília: IPEA/IPLAN, 1990.

FEIJÓ, Jandira. A essência da Governança Solidária Local. In: Olhares sobre a experiência da Governança Solidária Local de Porto Alegre. Porto Alegre: EDIPUCRS, 2008.

FUKUYAMA, Francis. Confiança: As virtudes sociais e a criação da prosperidade. Rio de Janeiro, Rocco, 1996.

GONZÁLEZ, Rodrigo. Capital social, ação coletiva e orçamento participativo. In: BAQUERO, Marcello (org.) Reinventando a sociedade na América Latina: cultura política, gênero, exclusão e capital social. Porto Alegre / Brasília: Ed. Universidade/Conselho Nacional dos Direitos da Mulher, 2001 
HABERMAS, Jurgen. Direito e democracia: entre a/actividade e a validade. Rio de Janeiro, Tempo Brasileiro, 2 v. Tradução de Factivity and Validity: Flávio Beno Siebeneichler. 1997.

HABERMAS, Jürgen. Teoria de la Accion Comunicativa. Madri: Taurus, 2000.

HANIFAN, Lyda Johnson. The rural school community center. In: Annals of the American Academy of Political and Social Science, $\mathrm{n}^{\circ} .67,1916$

HERMANY, Ricardo. (Re)discutindo o espaço Local.uma abordagem a partir do direito social de Gurvitch. Santa Cruz do Sul: Edunisc/IPR, 2007

INGLEHART, Ronald. Modernization and postmodernization: cultural, economic, anda political chance in 43 societies. Princeton: Princeton University Press, 1997

LEAL, Rogério Gesta. Estado, Administração Pública e sociedade: novos paradigmas. Porto Alegre: Livraria do Advogado, 2006

LEAL, Rogério Gesta. Os pressupostos epistemológicos e filosóficos da gestão de politicas públicas no estado democrático de direito. In: Direitos sociais e políticas públicas: desafios contemporâneos. Santa Cruz do Sul: EDUNISC, 2003.

MARSHALL, T. H. Cidadania, classe social e status. Trad. De Meton Porto Gadelha. Rio de Janeiro: Zahar Editores, 1967.

PAUGAM, Serge. La disqualification socieale (Essais sur la nouvelle pauvreté). Paris: PUF, 1991.

PERIUS, Vergílio Frederico. Cooperativismo e lei. São Leopoldo: Editora UNISINOS, 2001, p. 274.

PUTNAM, Robert. Making Democracy Work: Civic Traditions in Modern Italy, EDITORA. 1993.

SANTOS JÚNIOR, O. A.; AZEVEDO, S.; QUEIROZ RIBEIRO, L. C. Democracia e gestão Local: a experiência dos conselhos municipais no Brasil. In: Governança democrática e poder Local: a experiência dos conselhos municipais no Brasil. Rio de Janeiro: Revan, Fase 2004.

TEIXEIRA, Elenaldo Celso. O Local e o global: limites e desafios da participação cidadã. 2. ed. São Paulo: Cortez; Recife: EQUIP; Salvador: UFBA, 2001

Recebido para publicação 18/08/2008

Aceito para publicação 18/12/2008 